\title{
ECOLOGICAL COSTS AND BENEFITS CORRELATED WITH TRYPSIN PROTEASE INHIBITOR PRODUCTION IN NICOTIANA ATTENUATA
}

\author{
Grit A. Glawe, Jorge A. Zavala, André Kessler, Nicole M. van Dam, ${ }^{1}$ and Ian T. Baldwin ${ }^{2}$ \\ Department of Molecular Ecology, Max Planck Institute for Chemical Ecology, Jena 07745 Germany
}

\begin{abstract}
Genotypes of the wild tobacco Nicotiana attenuata from different geographic regions in North America vary considerably in the level of constitutive and inducible trypsin protease inhibitors (TrypPIs), a potent direct defense, as well as in the production of herbivore-induced volatiles that function as indirect defense. Genotypes collected from Arizona were found to lack the ability to produce TrypPIs at a transcriptional level, had decreased volatile production, but exhibited nicotine and growth responses that were not distinguishable from genotypes collected in Utah. In field trials with naturally occurring herbivores and in lab experiments with Manduca sexta larvae, Arizona genotypes were damaged more and sustained greater herbivore growth than the Utah genotypes. When Arizona and Utah genotypes were grown in competition, Arizona genotypes produced significantly more seed capsules than the Utah neighbor did. Moreover, jasmonate elicitation, which dramatically increased TrypPI production in only the Utah genotypes, reduced lifetime fitness measures of the Utah genotypes more than of the Arizona genotypes, demonstrating that TrypPI production is correlated with a fitness cost. The loss of both a direct and an indirect defense suggests a functional linkage between these types of defense.
\end{abstract}

Key words: chemical polymorphism, costs; genetic variation; herbivory; induced defenses; intraspecific plant competition; Nicotiana attenuata; phenotypic plasticity; phenotypic variation; protease inhibitors; volatile emission.

\section{INTRODUCTION}

Plants respond to herbivore attack with the induction of direct and indirect chemical defenses (Karban and Baldwin 1997). Resistance is known to vary among individuals from the same species and this variation is thought to be maintained by trade-offs between the benefits of reduced herbivory and the costs of resistance (Coley et al. 1985, Herms and Mattson 1992, Karban and Baldwin 1997). For example, inducible expression of resistance is thought to be a "cost-savings" measure that allows plants to forgo the costs of defense when it is not needed and time the expression of resistance traits with the need for defense (Baldwin 1998). Studies of resistance polymorphisms within and among populations suggest that this interplay of costs and benefits constitutes an important selection pressure. Variation in cyanogenesis in Trifolium repens appears to depend on mollusk density, which generates the fitness benefit (Dirzo and Harper 1982a, b), and the probability of frost, which may make the defense costly (Daday 1954). Resistance costs may arise from processes internal to the plant, such as from the allocation of fitness-limiting resources to defense metabolite production, and from processes external to the plant, for

Manuscript received 10 December 2001; revised 6 June 2002; accepted 10 June 2002. Corresponding Editor: R. F. Denno.

${ }^{1}$ Present address: Netherlands Institute of Ecology (NIOO-KNAW), P.O. Box 40, 6666 ZG Heteren, The Netherlands.

${ }^{2}$ Address correspondence to this author. E-mail: baldwin@ice.mpg.de example when resistant plants are unable to attract pollinators. Evidence for both ecological and allocation costs is found in studies on induced defenses in $\mathrm{Ni}$ cotiana attenuata, which invests $8 \%$ of its whole-plant nitrogen budget in nicotine production alone after herbivore attack and withdraws nicotine from the outer parts of its flowers when advertising for pollinator services (Baldwin 2001)

Evidence for the existence of resistance costs from studies using constitutively and inducibly expressed resistance is increasing (Bergelson and Purrington 1996, van Dam and Baldwin 2001, Heil and Baldwin 2002). The interpretation of these studies, however, is not trivial. For example, genes that control the expression of defensive traits may have pleiotropic effects on fitness traits (Elle et al. 1999). Similarly, fitness differences between induced and uninduced plants may be due to pleiotropic effects of the elicitor used to activate the induced resistance, rather than the expression of the resistance traits themselves (Creelman and Mullet 1997). Ideally, one should assess costs and benefits of inducible defenses in plants that differ only in the genes that control the expression of induced resistance but otherwise are genetically identical (Bergelson and Purrington 1996).

An additional complication is that the expression of resistance traits is often dependent on environmental conditions. This contingency may have been the cause of failures to detect costs of resistance (e.g., Brown 1988). Resistance costs thus may be more readily detected when plants are grown under environmental 
stresses, which simulate those that predominate in natural plant populations (Bergelson 1994, Karban and Baldwin 1997). For example, the fitness costs of jasmonate-induced defenses were only observed when $N$. attenuata plants were grown in competition with other uninduced plants (van Dam and Baldwin 1998, 2001).

Nicotiana attenuata, a postfire annual wild tobacco inhabiting the Great Basin Desert, has a number of well-described herbivore-induced direct and indirect defenses (Baldwin 2001). In addition to nicotine, the plants also produce serine protease inhibitors (PIs) after herbivore attack (van Dam et al. 2001b). Protease inhibitors are among the best studied defensive chemicals in plants (Ryan 1990, Jongsma et al. 1994, Heath et al. 1997, Koiwa et al. 1997). Protease inhibitors have been found to reduce herbivore growth in plants that were transformed with a heterologous PI gene (Hilder et al. 1987, Johnson et al. 1989). Genetic manipulations of wound signal transduction cascades (systemin, jasmonic acid) that resulted in increased PI expression also increased insect resistance (McGurl et al. 1992, Howe et al. 1996), but these signaling cascades regulate many other traits in addition to PIs (Bergey et al. 1996). Surprisingly, we are not aware of any study that has altered the expression of an endogenous PI gene to examine its defensive function.

Unlike nicotine induction, which is not inhibited by nitrogen stress (Ohnmeiss and Baldwin 1994) and is only inhibited by unnatural growing conditions in some species (e.g., pot-bound roots; Baldwin 1988), PI accumulation is contingent on plant growth parameters and nutrient supply. Van Dam et al. (2001b) found diurnal fluctuations in PI activity in leaves of $N$. attenuata rosette plants and an increase in PI activity with plant development. Nutrient stress apparently constrained both constitutive as well as induced levels in Brassica napus when plants were grown at high densities (Cipollini and Bergelson 2001).

In addition to eliciting the production of direct defenses, herbivore attack on $N$. attenuata plants elicits the release of a bouquet of volatile organic carbons (VOCs), which function as a potent indirect defense. Volatile organic carbon emission can reduce the herbivore load of the plant by $>90 \%$ in nature because it attracts a generalist predator and reduces herbivore oviposition rates (Kessler and Baldwin 2001). In comparison to the resource demands of induced nicotine production, the resource allocation to VOC production is trivial (Halitschke et al. 2000). The composition of the VOC release is known to vary among $N$. attenuata genotypes collected from different geographic locations, with the release of cis- $\alpha$-bergamotene being the most consistently released component of the herbivoreinduced VOC bouquet (Halitschke et al. 2000). Hence, if costs are responsible for maintaining the variation in VOC components, these costs are likely to be "ecological costs" rather than resource allocation costs.
In this paper, we survey the variation in direct and indirect defenses of $N$. attenuata collected across the geographical range of the species. We find nicotine induction to be invariable, while both trypsin protease inhibitor (TrypPI) activity and the composition of the induced VOC emissions are highly variable between plants from different geographical sites. Here we report a naturally occurring genotype pool that is unable to produce TrypPIs constitutively or after herbivore or methyl jasmonate elicitation. We show that the inability to produce TrypPI proteins is due to an inability to produce TrypPI mRNA. The TrypPI-deficient and TrypPI-producing genotypes were found to differ in their acceptability and susceptibility to four naturally occurring herbivores in the field. We compared the fitness of the TrypPI-deficient and TrypPI-producing genotypes in a competitive experiment, with and without methyl jasmonate elicitation, to examine the fitness costs associated with inducible and constitutive TrypPI production. These experiments show that TrypPI induction may be correlated with a fitness cost when TrypPI-producing plants grow in competition with plants that lack TrypPI production.

\section{Methods \\ Plant growth}

Seed collections of Nicotiana attenuata Torr. Ex Watson (Solanaceae) populations were made across western North America. Seeds used in this study were from 1996 field collections from three different geographic regions: (1) Arizona (A), a bulk collection from a 20-plant population near Flagstaff, Arizona; (2) California (C), a bulk collection from a 50-plant population near Benton, California; and (3) Utah (U), a bulk collection from a 1000-plant population near Apex Mine, in southwestern Utah. Seeds of these three populations were from the pooled collection of 20-30 plants from three (A and C) or two generations (U) of growth and selfing in the greenhouse. Seeds used in the experiments, therefore, represent a sample of the genetic variation present at the collection locality with minimal differences due to maternal effects.

Seeds were germinated in diluted liquid smoke solution as described in Baldwin et al. (1994). After 14 $\mathrm{d}$, seedlings for the phenotypic comparison were transferred to communal hydroponic chambers and 6-7 d later to 1-L individual pots with "No-N" solution supplemented with $2 \mathrm{mmol} / \mathrm{L} \mathrm{KNO}_{3}(\mathrm{Ohnmeiss}$ and Baldwin 1994). Every week plants received an additional $1 \mathrm{mmol} \mathrm{KNO}_{3}$, and every two weeks the complete hydroponic solution was replaced. Seedlings for the competition experiment were transplanted to $2-\mathrm{L}$ pots containing a 1:1 mixture of peat-perlite and "High N" (van Dam and Baldwin 1998). Two seedlings of similar size and appearance were planted $7 \mathrm{~cm}$ apart in each pot. Seedlings that were used for the feeding experiment were transplanted into individual $1-\mathrm{L}$ pots con- 
taining peat-perlite mixture. The peat-perlite was supplemented with "High N" according to the formula of van Dam and Baldwin (1998). All plants were placed in a climate chamber set at $32^{\circ} \mathrm{C}$ during $16 \mathrm{~h}$ light and $27^{\circ} \mathrm{C}$ during $8 \mathrm{~h}$ dark, with $65 \%$ relative humidity, and with $1000-1500 \mu \mathrm{mol} \cdot \mathrm{m}^{-2} \cdot \mathrm{s}^{-1} \mathrm{PPFD}$ at plant growing level. For the field experiments, seedlings were transplanted to roottrainers (Hummert, Earth City, Missouri, USA) containing the peat-perlite mixture and grown in a shade house for $\sim 14 \mathrm{~d}$ before being transplanted to an experimental garden at the Lytle Preserve, Santa Clara, Utah. Plants that provided the leaf material for the choice tests were transplanted into individual 2-L pots and maintained in the shade house.

\section{Plant elicitation}

The application of jasmonic acid or its methyl ester methyl jasmonate (MJ) or oral secretion (OS) is known to elicit the synthesis of herbivore-induced defense metabolites in $N$. attenuata, such as nicotine (Winz and Baldwin 2001), protease inhibitors (van Dam et al. $2001 b$ ), or VOC (Halitschke et al. 2000). In previous experiments, the application of $250 \mu \mathrm{g}$ MJ was found to elicit insect resistance (against Manduca sexta larvae; van Dam et al. 2001a) and to provide a convenient method of reproducibly eliciting changes in nicotine, protease inhibitors (PIs), or VOCs to an extent comparable to that elicited by herbivore attack (Baldwin et al. 1998, Baldwin 1998, 2001, Halitschke et al. 2000, Kessler and Baldwin 2001, van Dam et al. 2001b). Methyl jasmonate was used to induce nicotine and TrypPIs in plants from the three different populations as follows: $20 \mu \mathrm{L}$ of lanolin containing $250 \mu \mathrm{g}$ MJ was applied to two fully expanded leaves of each plant (Baldwin and Schmelz 1996). Control plants were treated similarly with $20 \mu \mathrm{L}$ pure lanolin. For VOC induction, plants were elicited with $M$. sexta oral secretions (OS) applied to a standardized mechanical wound (Halitschke et al. 2000). Two fully expanded leaves per plant were damaged by rolling a fabric pattern wheel 10 times over the leaf surface to create rows of puncture wounds into which $15 \mu \mathrm{L}$ OS from fourth or fifth instar larvae were applied (McCloud and Baldwin 1997). Controls remained untreated. Volatile organic carbon collection commenced $24 \mathrm{~h}$ after treatment. For the competition experiment, plants were transplanted to $2-\mathrm{L}$ pots, and after $10 \mathrm{~d}$ plants were elicited with either $150 \mu \mathrm{g}$ or $250 \mu \mathrm{g}$ MJ dissolved in $20 \mu \mathrm{L}$ lanolin.

\section{Protein, TrypPI, nicotine, and volatile measurements}

Protein and TrypPI concentrations were measured as described in van Dam et al. (2001b). Protease inhibitor activity is expressed as nmol/mg protein. Nicotine concentrations were measured by HPLC as described in Keinaenen et al. (2001) and expressed as mg/g fresh mass. For TrypPIs and nicotine, the maximum response is attained at $3 \mathrm{~d}$ and $4 \mathrm{~d}$, respectively. Because we used the same plants for TrypPI and nicotine measurements, we measured both TrypPI and nicotine content at $4 \mathrm{~d}$. The herbivore-induced VOC released from whole plants was trapped on activated charcoal for 8 $\mathrm{h}, 24 \mathrm{~h}$ after elicitation (the time of maximum release after a single elicitation; Halitschke et al. 2000) and measured by GC/MS as described in Halitschke et al. (2000). Volatile organic carbons were quantified using external standards and expressed in $\mathrm{ng} \cdot \mathrm{h}^{-1} \cdot \mathrm{L}^{-1}$ of air sampled.

\section{Phenotypic comparison of plants from different genotype pools}

Comparison of developmental and reproductive parameters. - Twenty-five plants from each genotype pool (A, C, and U) were grown in individual hydroponic chambers for $4 \mathrm{wk}$. Every $5 \mathrm{~d}$, five randomly selected plants from each genotype pool were harvested and measured. The following fitness estimates were measured: (1) whole plant biomass, (2) root mass, (3) shoot mass, (4) stalk length at 1 st d of flowering, (5) 1 st $\mathrm{d}$ of flowering, (6) number of branches, (7) number of flowers at day 25, and (8) number of seed capsules at day 25.

Comparison of direct and indirect defensive compounds.-For TrypPI and nicotine analysis, 10 soilgrown rosette-stage plants of each genotype pool were selected 2 wk after their transfer to $1-\mathrm{L}$ pots and randomly assigned to two treatment groups, control and methyl jasmonate (see Methods: Plant elicitation). Four days after treatments, the shoots were harvested to determine concentrations of TrypPIs and nicotine. For volatile measurements, 14 plants of each genotype pool were grown for $10 \mathrm{~d}$ in 1 -L hydroponic chambers and these plants received an additional $1 \mathrm{mmol} \mathrm{KNO}_{3}$ on the treatment day.

\section{Field experiments}

Field experiments were conducted to examine behavior and performance of naturally occurring herbivores on $\mathrm{A}$ and $\mathrm{U}$ genotypes. We chose the herbivores that were the most common consumers of $N$. attenuata in natural populations during the 2000 field season at Lytle Preserve, Santa Clara, in southwestern Utah, USA.

Choice tests.-Choice tests (bioassay) with the following field collected insects were used to examine herbivore preference between the A and U genotypes: (1) adult Trichobarus mucrorea (Coleoptera: Curculionidae), a weevil that feeds on leaves of several Solanaceae, such as Datura wrightii and N. attenuata; (2) adult Epithrix hirtipennis (Coleoptera: Chrysomelidae, Halticinae), a flea beetle specialist herbivore on tobacco that can cause severe damage at high population densities (Deseö et al. 1993); and (3) adult Trimerotropis spp. (Orthopteroidea: Caelifera), a generalist grasshopper which opportunistically feeds on N. atten- 
uata. Insects used in the bioassay were collected $24 \mathrm{~h}$ before the experiments started. Trichobarus mucrorea and Trimerotropis spp. were collected at the Lytle Preserve, Beaver Dam Wash, and E. hirtipennis was collected from a population of $N$. attenuata growing in a 1-yr-old burn at Apex Mine, Utah. All insects were transported to the laboratory and placed in polystyrene containers $(500 \mathrm{~mL})$; they received no food until the next day. Three days prior to start of each bioassay, potted plants in the elongation stage from both genotypes were elicited with $250 \mu \mathrm{g}$ of $\mathrm{MJ}$ in $20 \mu \mathrm{L}$ lanolin applied to the adaxial surface of two rosette leaves; this was designed to get a maximal induction of PIs. On day 3 , the second stalk leaf from all plants was harvested for protein and PI analyses while the first stalk leaf was collected for the choice test bioassays. Two same-sized leaves from A and U genotypes were placed $5 \mathrm{~cm}$ apart in a polystyrene container lined with wet paper towels to prevent wilting of the leaves. Each container held either three T. mucrorea, or five E. hirtipennis, or one Trimerotropis spp. Containers were kept in a trailer at ambient temperature, and after 48 $\mathrm{h}$ the amount of leaf area damaged was measured with graph paper. Seven replicate choice arenas were used for each herbivore species.

Colonization experiment.-We monitored the accumulation of leaf bugs (Tupiocoris notatus, Hemiptera: Miridae) on $N$. attenuata plants recently transplanted into an experimental garden. Commonly, T. notatus is the first insect species colonizing wild tobacco seedlings in the years following fires. Forty plants of each of the two populations were randomly planted in furrows, at a distance of $50 \mathrm{~cm}$ within and between the furrows. Plants were fertilized with water soluble NPK (14:14:13) every seven days. In contrast to the choice tests, plants in the experimental garden were not treated with MJ because we wanted to test the preference of herbivores for both populations displaying their constitutive phenotype. Two weeks after transplanting, the accumulation of $T$. notatus was measured by counting adult individuals on each single plant.

\section{Feeding experiment}

Because PIs are known to decrease protease activity in larval lepidopteran guts and reduce larval growth rates (Heath et al. 1997), we measured larval development on U and A plants. Eggs of Manduca sexta L. (Lepidoptera: Sphingidae) were obtained from Carolina Biological Supply Company (Burlington, North Carolina, USA) and placed in square polystyrene containers $(200 \mathrm{~mL})$ with clear lids that had been lined with a moist tissue. The containers were kept in climate chambers at $28^{\circ} \mathrm{C}$ and $65 \%$ relative humidity and a 16 : $8 \mathrm{~h}$ light:dark photoperiod until the eggs hatched. Freshly hatched Manduca sexta larvae were placed individually on 10 soil-grown rosette plants of each genotype pool. To prevent larvae from moving between plants, 1-L pots were placed $30 \mathrm{~cm}$ apart and each pot was shrouded with cardboard, providing a barrier to larval movement. Larval mass and instar were measured on the second, fifth, and seventh day after hatching. Each plant provided ample leaf material to supply one larva for the duration of the experiment.

\section{Competition experiment}

To examine whether inducible and constitutive TrypPI production incurs a fitness cost, we measured the correlation of plant fitness with TrypPI levels in A and $U$ plants that were not elicited, or were elicited with either $150 \mu \mathrm{g}$ or $250 \mu \mathrm{g}$ methyl jasmonate. We used a competition design that has been optimized to detect fitness effects of jasmonate-induced resistance in N. attenuata (van Dam and Baldwin 1998, 2001, Voelckel et al. 2001). Ten replicate pairs of plants were assigned to the following 12 treatment groups: untreated controls (1) A-A; (2) U-U; (3) A-U, and induced treatments (see Methods: Plant elicitation) (4) $\mathrm{A}-\mathrm{A}_{150}$, (5) $\mathrm{A}-\mathrm{A}_{250}$, (6) $\mathrm{U}-\mathrm{U}_{150}$, (7) $\mathrm{U}-\mathrm{U}_{250}$, (8) $\mathrm{A}_{150}-\mathrm{U}$, (9) $\mathrm{A}_{250}-$ $\mathrm{U}$, (10) $\mathrm{A}-\mathrm{U}_{150}$, (11) A-U $\mathrm{U}_{250}$, and (12) $\mathrm{A}_{150}-\mathrm{U}_{150}$. Every 2nd $\mathrm{d}$ for $6 \mathrm{wk}$ the pots were watered with $250 \mathrm{~mL}$ demineralized water to mimic the typical growth period in the plant's natural environment. Four days after induction, the source-sink transition leaf was harvested for TrypPI and nicotine analysis. The following fitness estimates were recorded from each plant: (1) stalk length after start of elongation for a period of $17 \mathrm{~d}$ and on the last day of watering, (2) the 1 st d of flowering (when the first flower had fully opened), and (3) the number of seed capsules 2 wk after last watering day. The number of seed capsules per plant reflects the lifetime reproductive output in $N$. attenuata under natural or greenhouse conditions (Baldwin 1998, Baldwin et al. 1998).

\section{RNA gel blot analysis}

The lack of TrypPI activity in the A genotypes prompted us to examine the accumulation of TrypPI mRNA. For RNA analysis, 20 shoots from each genotype pool, 10 from the $150 \mu \mathrm{g}$ MJ treatment and 10 from the untreated controls, were harvested from plants of the competition experiment $3 \mathrm{~d}$ after induction. Shoot tissues were pulverized in liquid nitrogen using a mortar and pestle. From this powder, total RNA was extracted using the acid guanidin thiocyanate-phenolchloroform method (Chomczynski and Sacchi 1987), which was modified by Ogawa et al. (1999) and is explained in detail in Winz and Baldwin (2001). RNA was quantified spectrophotometrically at 260,280 , and $320 \mathrm{~nm}$. RNA samples $(10 \mu \mathrm{g})$ were size fractionated using $1.2 \%$ (mass/volume) agarose-formaldehyde gel electrophoresis and Northern blotted onto nylon membrane (GeneScreenPlus, NEN-DuPont, Boston, Massachusetts, USA), as described in the manufacturer's protocol. Ethidium bromide staining of the gel prior to blotting revealed rRNA bands, which served as the loading control (Fig. 2 inset). The TrypPI gene of $N$. 
FIG. 1. Mean ( \pm 1 SE) dry whole-plant biomass of hydroponically grown plants of Nicotiana attenuata collected from Arizona (A), California (C), and Utah (U). Arrows indicate day of first flower production.

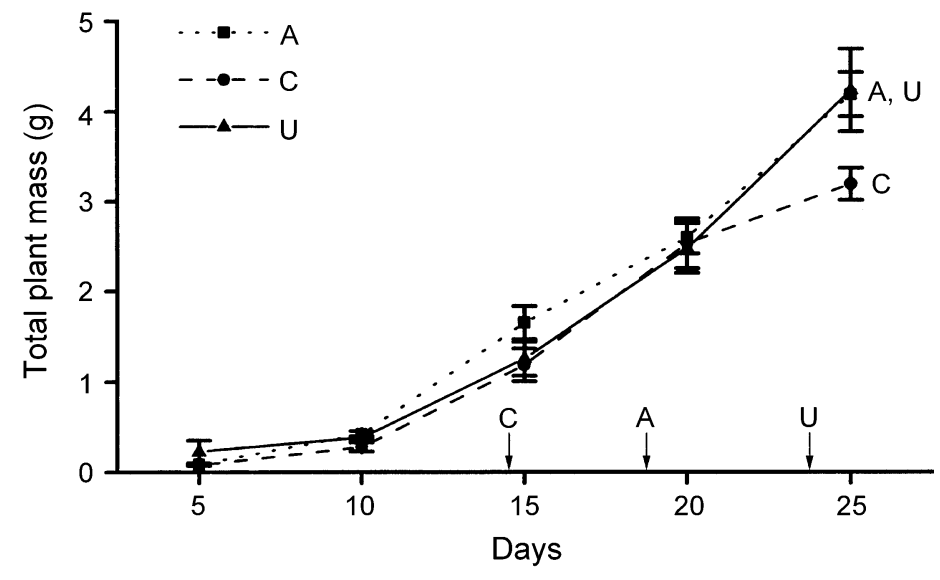

attenuata encodes a protein with seven repeat domains, each with a potential trypsin reactive site and putative signal peptides (K. Gase, D. Hui, A. Patankar, J. Zavala, and I. T. Baldwin, unpublished data). Probes ${ }^{32} \mathrm{P}$ labeled and specific for PI were prepared by PCR using $\left[\forall-{ }^{32} \mathrm{P}\right]$ $\mathrm{dCTP}$ in the reaction with the corresponding isolated PI plasmid as template. A primer pair (F, 5'-GAATTCGAGCTCGGTACCC-3' and R, 5'-GTCGACTCTAGAGGATCCCC- $3^{\prime}$ ) was designed allowing the amplification of the multidomain zone of the TrypPI gene. The area of TrypPI mRNA signal was quantified with Image Quant, Version 5.1 (Molecular Dynamics, Amersham Pharmacia Biotech, Buckinghamshire, UK).

\section{Statistical analysis}

Data were analyzed with StatView, Version 5.0 (SAS 1998). In all experiments TrypPI activity values and volatile release values were log transformed before analysis to meet requirements of normality. The TrypPI and protein data were analyzed by ANOVAs, and followed by Fisher's protected LSD post hoc comparisons in all experiments if the ANOVAs main effects were significant. Probability values from ANOVAs were corrected with the sequential Bonferroni correction for multiple comparisons whenever appropriate (Holm 1979). Differences in leaf damage in the choice tests were assessed by paired $t$ tests. Differences in colonization rates of leaf bugs were analyzed with repeatedmeasures ANOVA. Larval mass data were analyzed with repeated-measures ANOVA and a $G$ test was used to compare frequency distribution of larval instars. Data on developmental parameters and reproductive output from the competition experiment were analyzed by Wilcoxon signed-rank matched-pairs tests (WILCOX) for all comparisons to test for significant differences between competing plant pairs of both populations in one pot. Data on the mean differences and the percentage of mean differences (all proportions were arcsine square root transformed before analysis) in seed capsule number between the different plant pairs were analyzed by ANOVAs. The difference in capsule production between plants in one pot was calculated as $x-y$ ( $x$, capsule production on the plant with the most seed capsules; $y$, capsule production on the least productive plant), and the percentage difference between plants in one pot was calculated as $100 \%$ $-(y / x \times 100 \%)$. These values were averaged per treatment combination to obtain the mean differences and percentage mean differences.

\section{RESULTS}

\section{Developmental and reproductive parameters}

A repeated-measures comparison of total plant dry mass at all harvests found no significant differences among the three genotype pools $\left(F_{2,44}=2.62, P=\right.$ 0.1173 ), but at day 25 plants of the California (C) genotypes were significantly smaller than those of the Arizona (A) and Utah (U) genotypes (Fig. 1, Table 1). California genotypes had shorter stalks and more branches than plants of the A and U genotypes (Table 1), which gave $\mathrm{C}$ plants a bushier appearance. Moreover, plants of the $\mathrm{C}$ genotypes were the first to flower, and as a consequence of the greater number of branches, they produced the greatest number of seed capsules. Plants of A and U genotypes were remarkably similar in their developmental and reproductive parameters, differing only in the initiation of flowering (Fig. 1, Table 1). Plants of the A genotypes, on average, started flowering $5 \mathrm{~d}$ earlier than those of the U genotypes.

\section{Defensive compounds}

Plants from the $\mathrm{C}$ genotypes did not differ significantly from plants of the $U$ genotypes in any of the measured chemical defenses (ANOVA, PIs ${ }_{\mathrm{CON}}: F_{1,8}=$ $1.419, P=0.272$; $\mathrm{PIs}_{\mathrm{MJ}}: F_{1,8}=3.459, P=0.105$; nicotine $_{\mathrm{CON}}: F_{1,8}=0.311, P=0.594$; nicotine $_{\mathrm{MJ}}: F_{1,8}$ $=0.537, P=0.488$; cis- $\alpha$-bergamotene $\mathrm{CON}_{\mathrm{CN}}: F_{1,11}=$ $0.008, P=0.929$; cis- $\alpha$-bergamotene Wound + os $: F_{1,13}=$ $2.824, P=0.119$ ). Hence we report only comparisons between the $\mathrm{A}$ and $\mathrm{U}$ genotypes.

Nicotine.-No significant differences were found in either constitutive or methyl jasmonate-induced nico- 
TABLE 1. Differences at day 25 between plants of the three genotype pools of Nicotiana attenuata in developmental parameters and reproductive output.

\begin{tabular}{lccc}
\hline \hline \multirow{2}{*}{\multicolumn{1}{c}{ Measure }} & \multicolumn{2}{c}{$P$ values from genotype pool comparison $\dagger$} \\
\cline { 2 - 4 } & A vs. C & A vs. U & C vs. U \\
\hline Shoot dry mass (g) & 0.0530 & 0.5953 & 0.1354 \\
Root dry mass (g) & 0.1731 & 0.3353 & $\mathbf{0 . 0 3 0 5}$ \\
Whole plant dry mass (g) & $\mathbf{0 . 0 4 7 5}$ & 0.9157 & $\mathbf{0 . 0 3 9 1}$ \\
Stalk length (mm) & $\mathbf{0 . 0 0 5 2}$ & 0.2890 & $\mathbf{0 . 0 4 0 1}$ \\
Branches (no.) & $\mathbf{0 . 0 0 0 1}$ & 0.0532 & $\mathbf{0 . 0 0 0 1}$ \\
Days to first flower & $\mathbf{0 . 0 0 0 1}$ & $\mathbf{0 . 0 0 0 1}$ & $\mathbf{0 . 0 0 0 1}$ \\
Flowers (no.) & 0.5362 & 0.5004 & 0.2077 \\
Seed capsules (no.) & 0.2386 & 0.1934 & $\mathbf{0 . 0 2 2 5}$ \\
\hline
\end{tabular}

Notes: $P$ values are from one-way ANOVAs after Bonferroni correction for multiple comparisons. Bold type depicts significant differences at $P<0.05$.

$\dagger$ Arizona (A); California (C); and Utah (U).

tine content between both genotype pools (ANOVA, $\left.F_{1,8}<0.755 ; P>0.05\right)$. Both genotype pools exhibited a similar and significant increase in nicotine content after methyl jasmonate (MJ) elicitation (Fig. 2A; ANOVA, $F_{1,8}=39.137, P=0.0002$ ).

PIs and protein.-All plants of the $\mathrm{U}$ genotypes showed detectable constitutive PI activity and elicitation with $\mathrm{MJ}$ increased this activity up to 4.5 -fold (Fig. 2B; ANOVA, $\left.F_{1,8}=34.346, P=0.0004\right)$. In contrast, all A plants completely lacked constitutive or MJ inducible TrypPI activity (Fig. 2B). Protein levels were not significantly different between genotype pools. Northern blot analysis of the accumulation of TrypPI mRNA in the U genotypes revealed a fivefold increase in TrypPI mRNA after MJ elicitation (Fig. 2B). In contrast, TrypPI transcripts were not detectable in A plants, even after MJ induction (Fig. 2B). These results demonstrate that MJ-induced TrypPI activity is accompanied by increased TrypPI mRNA production and that the lack of TrypPI activity in the A genotypes results from a lesion in TrypPI transcript accumulation.

Volatile organic carbon.-Mechanical wounding and oral secretion (OS) application significantly increased whole-plant VOC emissions in U plants, as illustrated by the dramatic increase in cis- $\alpha$-bergamotene release (ANOVA, $F_{3,24}=4.253, P=0.0152$; Fisher's PLSD, $P=0.0176)$. However, OS elicitation of plants of the A genotype pool did not significantly

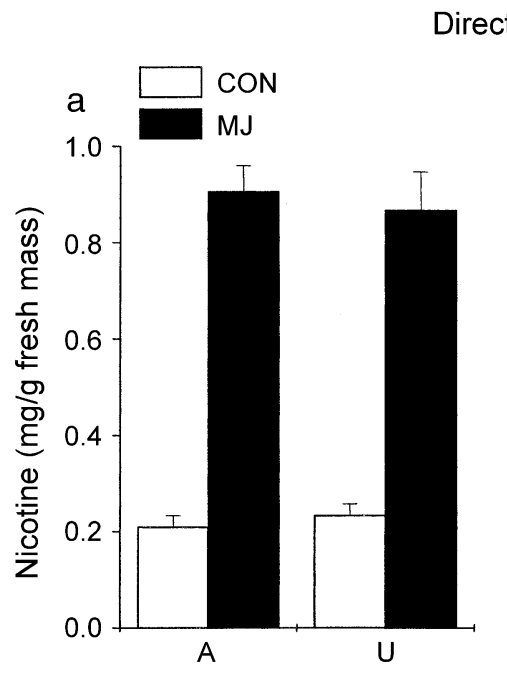

Direct defenses

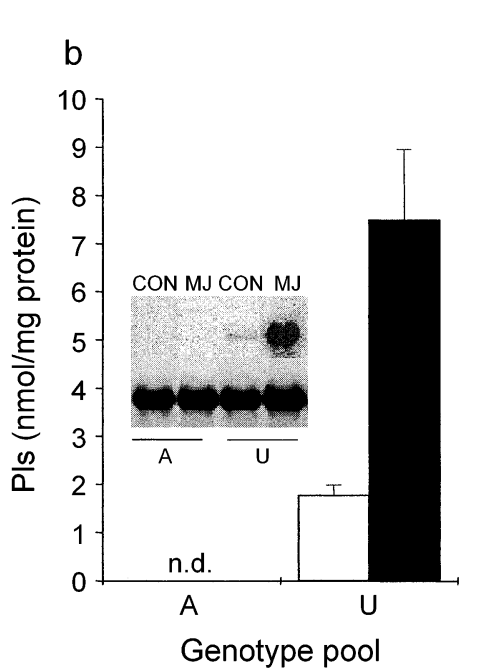

Indirect defenses

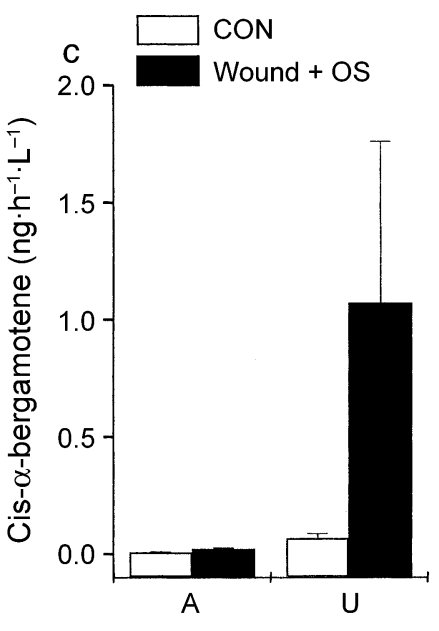

FIG. 2. Nicotiana attenuata plants from Arizona (A) and Utah (U) genotype pools differ enormously in their inducible direct and indirect defenses. (a) Constitutive (CON) and methyl jasmonate (MJ) induced nicotine contents (mean +1 SE) four days after elicitation with $250 \mu \mathrm{g}$ MJ. (b) Protease inhibitor levels (mean $+1 \mathrm{SE}$ ) for constitutive and MJ-induced TrypPIs four days after elicitation with $250 \mu \mathrm{g}$ MJ (n.d. = not detectable). Inset: Northern blot analysis of transcripts for uninduced controls (CON) and plants induced with $150 \mu \mathrm{g} \mathrm{MJ}$ (upper band, PI mRNA, $1.5 \mathrm{~kb}$; lower band, rRNA, $3.4 \mathrm{~kb}$ ). The lower band serves as a loading control. The same amount of RNA was loaded in each lane. (c) Mean $(+1 \mathrm{SE}) \mathrm{cis}-\alpha-$ bergamotene trapped from individual plants grown in whole plant chambers 24 hours after a single leaf (source-sink transition leaf) was wounded and treated with $20 \mu \mathrm{L}$ of Manduca sexta oral secretion (OS). Cis- $\alpha$-bergamotene is known to be the most consistent component of herbivore-induced volatile releases from all genotypes of $N$. attenuata. 

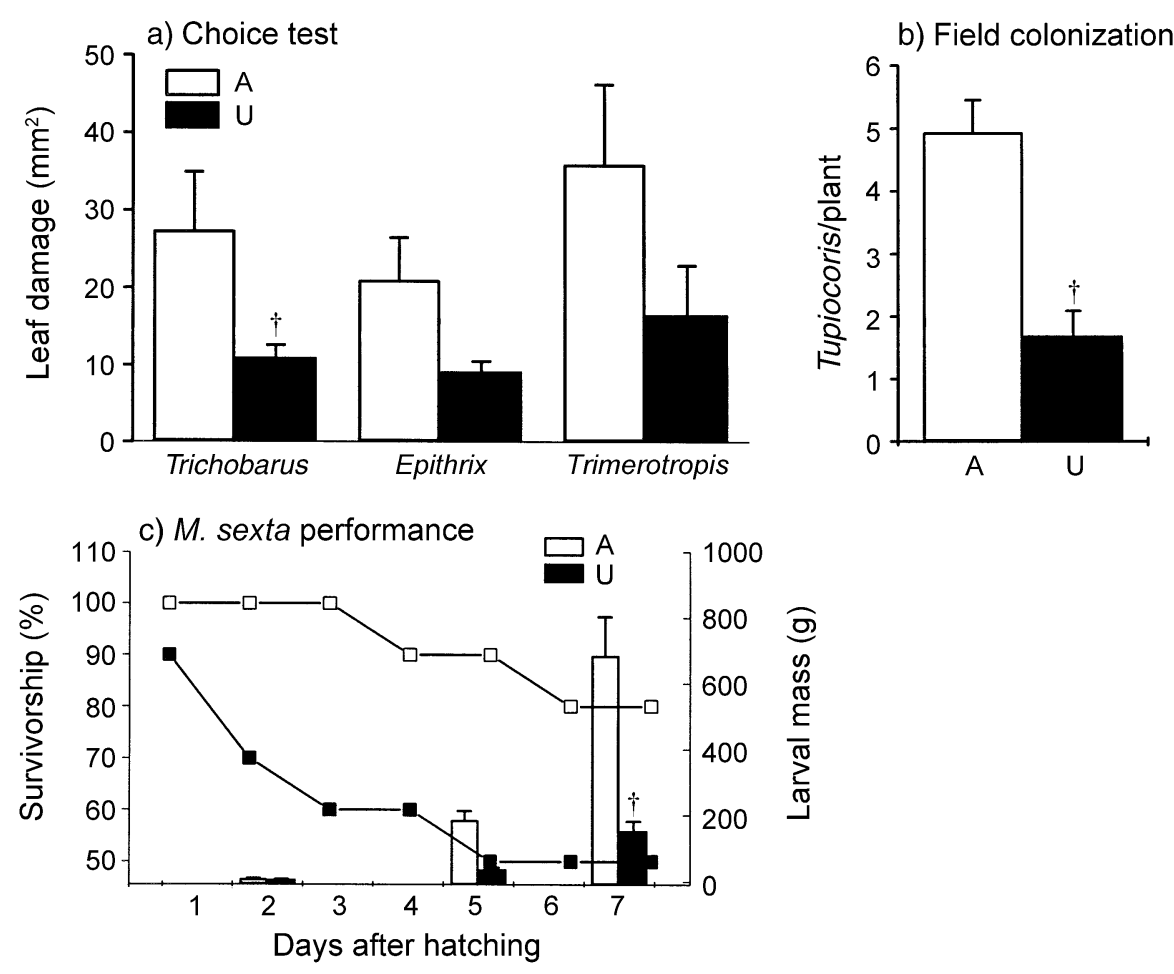

FIG. 3. The Utah (U) genotypes are more resistant to feeding from four insect species than the Arizona (A) genotypes. (a) Choice of Nicotiana attenuata first stalk leaves from Arizona and Utah plants made by three naturally occurring herbivores (Trichobarus mucrorea, Epithrix spp., and Trimerotropis spp.) in choice tests. Amount of leaf eaten was measured in square millimeters. Leaves were from bolting plants that had been elicited with $250 \mu \mathrm{g}$ methyl jasmonate applied to two rosettestage leaves. Values are the mean $(+1 \mathrm{SE})$ of seven replicate trials for each herbivore. (b) Mean $(+1 \mathrm{SE})$ number of Tupiocoris notatus bugs per plant two weeks after $\mathrm{A}$ and $\mathrm{U}$ genotypes of $N$. attenuata were transplanted into the field in a random spatial design. (c) Percentage survivorship and larval mass of Manduca sexta larvae feeding on soil-grown plants from hatching to age $7 \mathrm{~d}$. Values are the mean $(+1 \mathrm{SE})$ of 10 replicates for each genotype $(\dagger P<0.005)$.

increase VOC emission (Fig. 2C; Fisher's PLSD, $P=$ 0.9466). Overall, cis- $\alpha$-bergamotene emission of the $U$ genotypes was significantly higher (up to 50-fold) than that of the A genotypes (Fisher's PLSD, $P=0.0057$ ). The other quantified VOC constituents did not differ significantly in either control or induced plants between A and $\mathrm{U}$ genotype pools ( $P$ values from post hoc comparisons after ANOVA: linalool ${ }_{\mathrm{CON}}, P=0.5978$, linalool $_{\mathrm{WOUND}+\mathrm{OS}}, P=0.0631$; ocimene $_{\mathrm{CON}}, P=0.0756$, ocimene $_{\mathrm{WOUND}+\mathrm{OS}}, P=0.140$ ).

\section{Utah field experiments}

Choice tests.-Together the three herbivores removed significantly more leaf area from A genotypes leaves than from $\mathrm{U}$ genotypes leaves (Fig. 3A; paired $t$ test, $\left.t_{18}=2.916, P=0.0276\right)$. However, when compared per species, only the weevil Trichobarus mucrorea fed significantly more (up to 2.5-fold) on leaves of the A genotypes (Fig. 3A; $t_{6}=2.969, P=0.025$ ).

Field colonization.-About $10 \mathrm{~d}$ after transplantation to the field, Tupiocoris notatus adults began appearing on plants, where they were observed to feed and mate. After $2 \mathrm{wk}$, plants of the A genotypes had significantly more (up to 2.5-fold) of these leaf bugs than plants of the U genotypes (Fig. 3B; ANOVA, $F_{1,34}$ $=24.342, P<0.0001)$.

\section{Laboratory feeding experiment}

Manduca sexta larval development, larval mass and survivorship were significantly different between caterpillars fed on the two $N$. attenuata genotype pools (Fig. 3C; $G$ test for frequency distribution of larval instars, $G_{4}=11.54, P=0.021$; repeated-measures ANOVA on larval mass, $F_{1,18}=22.974, P=0.0001$ ). Larvae fed on U plants consistently had lower survivorship (50\% by day 7 ) and larval mass ( $~ 58 \%$ by day 7) than those fed on A plants for the duration of the experiment (Fig. 3C). By day 7, all 10 larvae on the A genotypes had reached the fourth instar, while on the U genotypes, only 1 out of 10 larvae had reached the fourth instar, 8 the third instar, and 1 the second instar. As expected, larval feeding for $7 \mathrm{~d}$ on plants significantly induced TrypPI production in the $\mathrm{U}$ genotypes (ANOVA, $F_{1,18}=24.785, P<0.0001$ ), but again no TrypPI activity was detected in the A genotypes. Protein concentrations decreased by $30 \%$ in both genotypes during the 7-d experiment. 
TABLE 2. Absolute and relative mean differences in lifetime seed capsule production for pairs of developmentally synchronized plants from the Arizona (A) or Utah (U) genotypes of Nicotiana attenuata.

\begin{tabular}{|c|c|c|c|c|}
\hline \multirow{2}{*}{$\begin{array}{l}\text { Competi- } \\
\text { tors }\end{array}$} & \multicolumn{2}{|c|}{$\begin{array}{l}\text { Absolute mean difference in } \\
\text { capsule number }\end{array}$} & \multicolumn{2}{|c|}{$\begin{array}{l}\text { Relative mean difference in } \\
\text { capsule number }\end{array}$} \\
\hline & Mean \pm 1 SE & $P$ & Mean $\pm 1 \mathrm{SE}$ & $P$ \\
\hline $\mathrm{AU}$ & $17.000 \pm 3.925$ & 0.0033 & $46.072 \pm 6.554$ & $<0.0001$ \\
\hline $\mathrm{A}_{150} \mathrm{U}_{150}$ & $23.625 \pm 7.744$ & 0.0157 & $56.887 \pm 10.390$ & 0.0002 \\
\hline $\mathrm{AA}_{150}$ & $16.889 \pm 4.228$ & 0.0109 & $35.164 \pm 5.602$ & $<\mathbf{0 . 0 0 0 1}$ \\
\hline $\mathrm{AA}_{250}$ & $23.456 \pm 4.660$ & 0.0098 & $44.762 \pm 4.489$ & $<\mathbf{0 . 0 0 0 1}$ \\
\hline $\mathrm{UU}_{150}^{250}$ & $13.700 \pm 6.556$ & 0.0080 & $46.625 \pm 7.818$ & $<\mathbf{0 . 0 0 0 1}$ \\
\hline $\mathrm{UU}_{250}$ & $16.200 \pm 3.463$ & 0.0069 & $61.101 \pm 7.325$ & $\mathbf{0 . 0 0 0 3}$ \\
\hline $\mathrm{AU}_{150}^{20}$ & $25.700 \pm 4.228$ & 0.0051 & $67.948 \pm 6.506$ & $<\mathbf{0 . 0 0 0 1}$ \\
\hline $\mathrm{AU}_{250}$ & $34.000 \pm 2.564$ & 0.0041 & $79.830 \pm 5.030$ & 0.0002 \\
\hline $\mathrm{A}_{150} \mathrm{U}$ & $-8.095 \pm 4.936$ & 0.0995 & $41.647 \pm 19.765$ & 0.2061 \\
\hline $\mathrm{A}_{250} \mathrm{U}$ & $-17.368 \pm 5.310$ & 0.0584 & $14.788 \pm 25.104$ & 0.5482 \\
\hline
\end{tabular}

Notes: Plants were either uninduced or induced with $150 \mu \mathrm{g}$ or $250 \mu \mathrm{g}$ of methyl jasmonate and grown in the same pot (see Fig. 4 for primary data). $P$ values are from one-way ANOVAs after arcsine square-root transformation. Bold type denotes significant differences at $P<0.05$.

\section{Competition experiment}

In order to estimate the fitness consequences associated with constitutive and inducible TrypPI production, we calculated the mean differences and the percentage mean differences in seed capsule production for several treatment groups in the competition experiment (Table 2). Unelicited plants of the A genotype pool were less sensitive to competition than U plants. Although stalk lengths of $U$ and A genotypes did not differ when they were grown in individual pots (Table 1), the stalks of plants in A with A pots were significantly taller than those of $U$ with $U$ pots (repeatedmeasures ANOVA, $F_{1,19}=12.811, P=0.002$ ). Capsule production, however, did not differ between these treatments (ANOVA, $F_{1,19}=2.17, P=0.1571$ ). When untreated A plants competed with uninduced U neighbors in the same pot, they not only had significantly taller stalks, but also flowered significantly earlier and produced significantly more seed capsules than their $\mathrm{U}$ neighbor (Table 2, Fig. 4A; WILCOX, $P_{\text {stalk }}=0.0051$, $\left.P_{\text {flower }}=0.0093, P_{\text {capsules }}=0.0033\right)$. The difference in seed production between unelicited plants of the two genotype pools in competition arose principally from a decrease in reproductive output of the $U$ genotypes, rather than an increase in the output of the A genotypes (Fig. 4A).

Methyl jasmonate elicitation of both genotype pools, when plants were competing with unelicited plants of the same genotype pool (Fig. 4B), reduced stalk length only for the U genotypes (WILCOX, $P_{\mathrm{U}, \mathrm{U} 150}=0.0284$, $\left.P_{\mathrm{U}, \mathrm{U} 250}=0.0051\right)$, and delayed flowering (all $\left.P \mathrm{~s}<0.05\right)$ and decreased seed capsule production in both genotype pools (all $P$ s $<0.05$ ). The absolute decreases in capsule production in the A genotypes (16-23 capsules) were larger than the absolute differences in the U genotypes (14-16 capsules), but the proportional differences were greater in the U genotypes (Table 2). Interestingly, the difference in the A genotype treatments resulted from both a decrease in the elicited pair member (representing a cost of elicitation) as well as an increase in capsule production of the unelicited pair member (representing an opportunity benefit). Both costs and opportunity benefits of elicitation were approximately equal and proportional to the degree of elicitation (Fig. 4B, Table 2). In contrast, the difference in the $U$ genotypes treatments resulted only from a decrease in capsule production of the elicited member of the pair (Fig. 4B). The difference between plants of the two genotype pools in their ability to realize an opportunity benefit profoundly influenced the fitness outcome of competition between plants of different genotype pools that were differentially induced with $\mathrm{MJ}$ (Fig. 4C). Elicitation of A plants competing with uninduced $U$ plants did not significantly reduce development or seed output compared to their neighbor (Fig. 4C). Although A plants that were elicited with the highest dose of MJ produced 17 capsules less than their unelicited U competitor, this difference was only marginally significant ( $P=0.0584$; Table 2 ). In contrast, elicited U plants competing with unelicited A plants, had significantly shorter stalks, flowered later, and produced fewer capsules (26-34 capsules, a 68-80\% relative difference; Fig. 4C, Table 2; WILCOX, all $P$ s $<$ $0.05)$. When both plants were elicited $\left(A_{150}, U_{150}\right)$, the outcome of the competition was similar to that of A with $U$ treatments, but with a larger (by six seed capsules) advantage for the $A_{150}$ genotypes over $U_{150}$ (Fig. $4 \mathrm{~A}, \mathrm{C}$, Table 2). Because nicotine induction is similar in both genotype pools, this increased fitness cost of induced $\mathrm{U}_{150}$ plants may reflect the costs of inducing PIs, and possibly also the costs correlated with VOC production, specific to the U genotype.

In summary, when unelicited A plants compete with unelicited U plants, the A plants produce, on average, 17 additional capsules, which is similar to the difference in capsule production when $U$ plants compete with highly elicited U plants (16.2 capsules; Table 2). Plants of the A genotypes, but not the $U$ genotypes, realize 

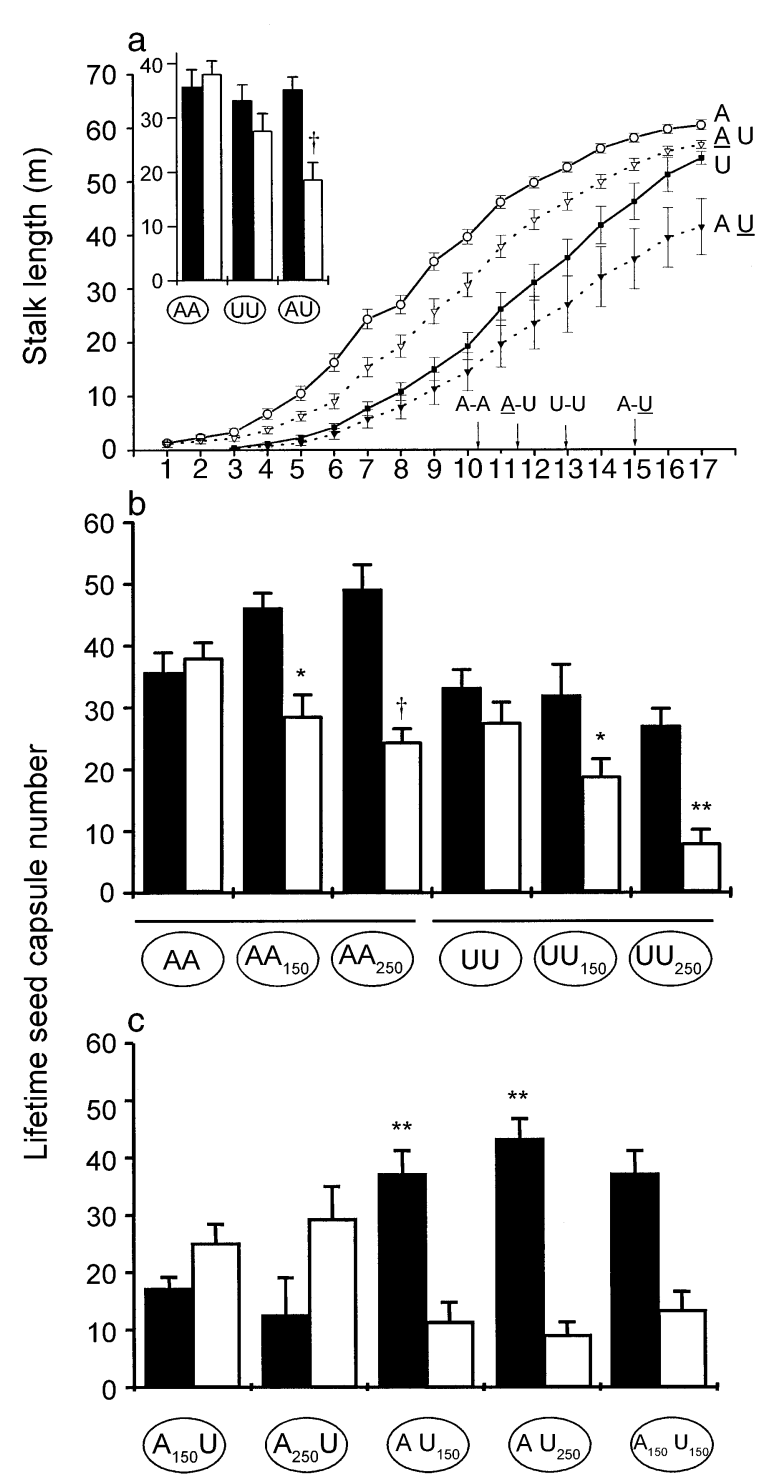

FIG. 4. Protease-inhibitor-deficient Nicotiana attenuata plants realize a significant fitness benefit when grown under intense intraspecific competition. Plants from the Arizona (A) and Utah (U) genotype pools were either uninduced or induced with $150 \mu \mathrm{g}$ or $250 \mu \mathrm{g}$ of methyl jasmonate (MJ) and grown in the same pot (symbols within ovals) in 12 different treatment groups. For all treatment groups, stalk length, days to first flower, and lifetime seed capsule production were analyzed as fitness estimates. (a) Treatments without MJ elicitation: mean $(+1 \mathrm{SE})$ stalk length, starting on the day with measurable stalk growth for 17 subsequent days, and mean (+1 SE) lifetime seed capsule production (inset). The solid lines for $\mathrm{A}$ and $\mathrm{U}$ represent the mean stalk lengths for AA and UU, respectively. Arrows depict the mean day of first flowering. (Significant differences: stalk length on day 17, $P_{\mathrm{A}-\mathrm{U}}=0.0290$; first flower, $P_{\mathrm{A}-\mathrm{U}}=0.0093$ ). A solid line under $A$ or $U$ identifies the member of the plant pair from which the data come. (b, c) Treatments with MJ elicitation: mean $(+1 \mathrm{SE})$ lifetime seed capsule number produced by plants in different treatment combinations. Symbols above columns indicates level of significant differences between members of a pair $(* P<0.05, * * P<0.01, \dagger P<0.005)$. In (c) only, the Arizona genotype is depicted by solid bars, and the Utah genotype by open bars. opportunity benefits when growing next to induced plants, which account for $\sim 50 \%$ of the fitness differences between induced and uninduced pairs. When a highly elicited $\mathrm{U}$ plant competes with an unelicited A plant, the difference is 34 capsules, half of which (17 capsules) can be attributed to the fitness benefit realized by the A plants, and the other half (17 capsules) agrees well with the estimates of the fitness costs borne by elicited and unelicited U genotype plants.

\section{Discussion}

Plants from populations from different geographical regions clearly differ in morphology, phenology, and defensive chemistry. The California (C) genotypes flower earlier and attain a smaller, bushier growth form than plants from genotype pools collected from Arizona (A) and Utah (U), and which, in turn, are phenologically and morphologically very similar (Fig. 1). Seeds from the $\mathrm{C}$ genotype pool were collected from a disturbed roadside habitat, while seeds from both $\mathrm{A}$ and $\mathrm{U}$ genotype pools were collected from populations growing in juniper-pine habitats that had burned the previous year. Possibly the earlier flowering $\mathrm{C}$ genotypes may realize a higher fitness in the microclimatic and disturbance regimes of roadside habitats, while later flowering genotypes may have an advantage in 1yr-old burns, with their modest herbivore loads (Baldwin 1998) and high soil nitrogen levels (Lynds and Baldwin 1997).

Dramatic differences in the chemistry mediating both direct (TrypPI) and indirect (VOC) defenses were found between plants of the two morphologically similar A and U genotype pools. The TrypPI-deficient and VOC-impaired A genotypes are the first reported natural ecotype to lack components of both an inducible direct and indirect defense. Protease inhibitor production is a widespread character in the Solanaceae (Koiwa et al. 1997), but the extent to which it is a genetically polymorphic trait is unknown. Additionally, the A genotypes do not increase cis- $\alpha$-bergamotene emissions after elicitation, although this VOC previously was the most consistently released component of herbivore-induced volatile bouquet from a number of $N$. attenuata populations (Halitschke et al. 2000). It is unclear whether the lack of VOC induction is, similar to the lack of TrypPI protein accumulation, associated with a deficiency in mRNA accumulation. Ongoing molecular work is addressing the mechanisms responsible for the lack of PI transcript accumulation and how this correlates with the lack of VOC emissions. The extent to which other uncontrolled and unmeasured defenses might account for reduced herbivore resistance and/or increased competitiveness remains an open question.

Plants of the two chemically distinct but morphologically similar genotype pools from Utah and Arizona were used to examine the costs and benefits associated with TrypPI production. The results of our bioassays and field colonization experiments (Fig. 3A, B) imply 
that the difference in PI levels may be responsible for the differences in resistance between plants of the two populations, because they did not differ in either induced or constitutive nicotine production. This is consistent with studies reporting that transformation of agricultural varieties with heterologous PIs can provide durable resistance against leaf-feeding herbivores (Johnson et al. 1989, Wolfson and Murdock 1990, Broadway and Colvin 1992, Jongsma et al. 1994, Heath et al. 1997; but see Winterer and Bergelson 2001). The dramatically lower performance of Manduca sexta larvae on plants of the U genotypes (Fig. 3C) is likely a response to both constitutive and induced PI activities. Moreover, M. sexta feeding decreased protein contents in leaf extracts of plants of both genotype pools, which may have exacerbated the effects of the protease inhibiting activities of the PI (Duffey and Stout 1996). However, conclusive evidence that PIs are directly responsible for the observed effects will require the silencing of the endogenous PI gene in the U genotypes or expressing the PI gene from the $\mathrm{U}$ genotypes in $\mathrm{A}$ plants.

On the other hand, the role of the VOCs in resistance appears to be in attracting predators and parasitoids to the feeding herbivores or reducing oviposition by adults (Dicke 1994, De Moraes et al. 1998, 2001, Kessler and Baldwin 2001). The experimental enhancement of cis- $\alpha$-bergamotene emissions in the field is known to dramatically attract a generalist predator (Kessler and Baldwin 2001), but whether plant genotypes that lack the ability to release this and other VOCs are unable to attract predators when attacked is unknown. Since the volatiles that potentially attract herbivores to their host plants are unknown for insects used in our bioassays, their choices may reflect an avoidance of plants releasing VOCs to avoid potentially higher predation pressure as well as PI-laced tissues. Predator avoidance may have contributed to the strong preference of Tupioccoris for the A genotypes in the field plantation.

While our experiments demonstrate that producing TrypPIs is correlated with insect resistance, our results also show that there is an opportunity cost associated with PI production. The competitively mediated cost of constitutive and inducible PI and VOC production was correlated with an opportunity benefit for the TrypPI and VOC deficient A genotype growing adjacent to a TrypPI and VOC producing $U$ genotype. Plants of the $\mathrm{U}$ genotype pool, in contrast, were not able to realize an opportunity benefit when growing in competition with a methyl jasmonate-treated plant of either genotype pool. The fitness consequences, which are associated with both constitutive and inducible TrypPI production (and possibly VOC emission), are large: the observed 17 capsule differences represent a decrease of $\sim 46 \%$ in reproductive output (Fig. 4 , Table 2 ). The fitness consequences associated with inducible TrypPI production and VOC emission can be estimated by comparison of differences in seed capsules between A with $U$ and $A_{150}$ with $U_{150}$ treatments. Elicitation of plants of both genotype pools increased the difference between plants in one pot by six capsules, a fitness cost of $\sim 20 \%$. Again tests of the hypothesis that PI production might be directly responsible for the observed fitness differences await competition experiments with plants from the A genotype pool transformed to express TrypPIs and plants from the U genotype pool with silenced TrypPI genes.

Our results differ from those obtained in earlier experiments with tomato in which TrypPI accumulation was elicited with chitin injections (Brown 1988). In these experiments, seed output of chitin-treated plants was indistinguishable from that of untreated control plants, despite the large difference in inhibitor contents. Tomato appears to be particularly well buffered against decreases in seed and fruit production (Thaler 1999), and the plants were grown in individual containers with high nitrogen supply rates. Thus plants actually might only incur the cost of inhibitor production when competing with others, making the costs of PI production mainly opportunity costs (van Dam and Baldwin 1998, 2001).

Because PI production is a heritable trait (N. M. van Dam, unpublished data) and involves both costs and benefits, natural selection may act on PI levels in $N$. attenuata. The geographic location (e.g., altitude) of plant populations may be of importance for the level of a chemical defense, because it is linked with the intensity of herbivore pressure that plants experience (Daday 1954, Carey and Wink 1994, Salmore and Hunter 2001). The Utah and Arizona populations are separated by the Grand Canyon, $>500 \mathrm{~km}$ in distance, and $2 \mathrm{~km}$ in height above sea level and hence are likely to have minimal direct gene flow between them.

Given this geographic isolation, it is tempting to speculate that the functional linkage between PI (or other unmeasured direct defenses) and VOC production is adaptive, as PI expression frequently slows the growth rate of insect herbivores by making their digestive processes less efficient (Charity et al. 1999, Mochizuki et al. 1999, Cloutier et al. 2000, Winterer and Bergelson 2001). Hence the fitness benefits of PI expression may result from extending the period during which larvae can be successfully attacked by natural enemies. Moreover, expression of VOCs without direct defenses that slow the growth of herbivores may represent a liability if these VOCs allow potential herbivores to locate host plants (Kalberer et al. 2001). Alternatively, the correlated loss of herbivore-induced VOC and TrypPI production in the A genotypes may be caused by random effects, such as genetic drift or founder effects (Maynard-Smith 1989).

\section{ACKNOWLEDGMENTS}

We thank the Max Planck Gesellschaft for financial support, Evelyn Claussen for assistance with the figures, Thomas 
Janßen for assistance with the PI assays, and Brigham Young University for use of their Lytle Preserve as a field station.

\section{Literature Cited}

Baldwin, I. T. 1988. Damage-induced alkaloids in tobacco: pot-bound plants are not inducible. Journal of Chemical Ecology 14:1113-1120.

Baldwin, I. T. 1998. Jasmonate-induced responses are costly but benefit plants under attack in native populations. Proceedings of the National Academy of Science, USA 95: 8113-8118.

Baldwin, I. T. 2001. An ecological-motivated analysis of plant-herbivore interactions in native tobacco. Plant Physiology 127:1449-1458.

Baldwin, I. T., D. Gorham, E. A. Schmelz, C. Lewandowski, and G. Y. Lynds. 1998. Allocation of nitrogen to an inducible defense and seed production in Nicotiana attenuata. Oecologia 115:541-552.

Baldwin, I. T., and E. A. Schmelz. 1996. Immunological memory in the induced accumulation of nicotine in wild tobacco. Ecology 77:236-246.

Baldwin, I. T., L. Staszakkozinski, and R. Davidson. 1994. Up in smoke. 1. Smoke-derived germination cues for postfire annual, Nicotiana attenuata Torr. Ex Watson. Journal of Chemical Ecology 20:2345-2371.

Bergelson, J. 1994. The effects of genotype and the environment on costs of resistance in lettuce. American Naturalist 143:349-359.

Bergelson, J., and C. B. Purrington. 1996. Surveying patterns in the cost of resistance in plants. American Naturalist 148 : 536-558.

Bergey, D. R., G. A. Howe, and C. A. Ryan. 1996. Polypeptide signalling for plant defensive genes exhibit analogies to defense signalling in animals. Proceedings of the National Academy of Science, USA 93:12053-12058.

Broadway, R. M., and A. A. Colvin. 1992. Influence of cabbage proteinase inhibitors in situ on the growth of larval Trichoplusia ni and Pieris rapae. Journal of Chemical Ecology 18:1009-1024.

Brown, D. G. 1988. The cost of plant defense: an experimental analysis with inducible proteinase inhibitors in tomato. Oecologia 76:667-670.

Carey, D. B., and M. Wink. 1994. Elevational variation of isoquinoline alkaloid contents in a lupine (Lupinus argentus) of the Rocky Mountains. Journal of Chemical Ecology 20:849-857.

Charity, J. A., M. A. Anderson, D. J. Bittisnich, M. Whitecross, and T. J. V. Higgins. 1999. Transgenic tobacco and peas expressing a proteinase inhibitor from Nicotiana alata have increased insect resistance. Molecular Breeding 5 : $357-365$.

Chomczynski, P., and N. Sacchi. 1987. Single-step method of RNA isolation by acid guanidin thiocyanate-phenolchloroform extraction. Annals of Biochemistry 162:156159.

Cipollini, D. F., and J. Bergelson. 2001. Plant density and nutrient availability constrain constitutive and wound-induced expression of trypsin inhibitors in Brassica napus. Journal of Chemical Ecology 27:593-610.

Cloutier, C., C. Jean, M. Fournier, S. Yelle, and D. Michaud. 2000. Adult Colorado potato beetles, Leptinotarsa decemlineata compensate for nutritional stress on oryzacystatin I-transgenic potato plants by hypertrophic behavior and over-production of insensitive proteases. Archives in Insect Biochemistry and Physiology 44:69-81.

Coley, P. D., J. P. Bryant, and F. S. Chapin III. 1985. Resource availability and plant antiherbivore defense. Science 230: 895-899.

Creelman, R. A., and J. E. Mullet. 1997. Biosynthesis and action of jasmonates in plants. Annual Review of Plant Physiology and Molecular Biology 48:355-381.
Daday, H. 1954. Gene frequencies in wild populations of Trifolium repens. I. Distribution by latitude. Heredity 8: 61-78.

De Moraes, C. M., J. W. Lewis, P. W. Pare, H. T. Alborn, and J. H. Tumlinson. 1998. Herbivore-infested plants selectively attract parasitoids. Nature 393:570-573.

De Moraes, C. M., M. C. Mescher, and J. H. Tumlinson. 2001. Caterpillar-induced nocturnal plant volatiles repel conspecific females. Nature 410:577-580.

Deseö, K. V., A. Balabiani, L. Sannino, and G. Zampelli. 1993. Zur Biologie und biologischen Bekämpfung des Tabakkäfers, Epithix hirtipennis in Italien. Anzeiger für Schädlingskunde, Pflanzenschutz, Umweltschutz 66:2629.

Dicke, M. 1994. Local and systemic production of volatile herbivore-induced terpenoids. Journal of Plant Physiology 143: 165-172.

Dirzo, R., and J. L. Harper. 1982a. Experimental studies on slug-plant interactions. III. Differences in the acceptability of individual plants of Trifolium repens to slugs and snails. Journal of Ecology 70:101-117.

Dirzo, R., and J. L. Harper. 1982b. Experimental studies on slug-plant interactions. IV. The performance of cyanogenic and acyanogenic morphs of Trifolium repens in the field. Journal of Ecology 70:119-138.

Duffey, S. S., and M. J. Stout. 1996. Anti-nutritive and toxic components of plant defense against insects. Archives of Insect Biochemistry and Physiology 32:3-37.

Elle, E. E., N. M. van Dam, and J. D. Hare. 1999. Cost of glandular trichomes, a 'resistance' character in Datura wrightii Regel (Solanaceae). Evolution 53:22-35.

Halitschke, R., A. Kessler, J. Kahl, A. Lorenz, and I. T. Baldwin. 2000. Eco-physiological comparison of direct and indirect defenses in Nicotiana attenuata. Oecologia 124:408417.

Heath, R. L., G. McDonald, J. T. Christeller, M. Lee, K. Bateman, J. West, R. Vanheeswick, and M. A. Anderson. 1997. Proteinase inhibitors from Nicotiana alata enhance plant resistance to insect pests. Journal of Insect Physiology 43:833-842.

Heil, M., and I. T. Baldwin. 2002. Fitness costs of induced resistance-the emerging experimental support for a slippery concept. Trends in Plant Science 7:61-67.

Herms, D. A., and W. J. Mattson. 1992. The dilemma of plants: to grow or to defend. Quarterly Review of Biology 67:283-335.

Hilder, V. A., A. M. R. Garehouse, S. E. Sheerman, R. F. Barker, and D. Boulter. 1987. A novel mechanism of insect resistance engineered into tobacco. Nature 330:160-163.

Holm, S. 1979. A simple sequentially rejective multiple test procedure. Scandinavian Journal of Statistics 6:65-70.

Howe, G. A., J. Lightner, J. Browse, and C. A. Ryan. 1996. An octadecanoid pathway mutant of tomato is compromised in signaling for defense against insect attack. Plant Cell 8:2067-2077.

Johnson, R., J. Narvaez, G. An, and C. A. Ryan. 1989. Expression of proteinase inhibitors I and II in transgenic tobacco plants: effects on natural defense against Manduca sexta larvae. Proceedings of the National Academy of Science, USA 86:9871-9875.

Jongsma, M. A., P. L. Bakker, B. Visser, and W. J. Stiekema. 1994. Trypsin inhibitor activity in mature tobacco and tomato plants is mainly induced locally in response to insect attack, wounding, and virus infection. Planta 195:29-35.

Kalberer, N. M., T. C. J. Turlings, and M. Rahier. 2001. Attraction of a leaf beetle (Oreina cacaliae) to damaged host plants. Journal of Chemical Ecology 27:647-661.

Karban, R., and I. T. Baldwin. 1997. Induced responses to herbivory. University of Chicago Press, Chicago, Illinois, USA. 
Keinaenen, M., N. J. Oldham, and I. T. Baldwin. 2001. Rapid HPLC screening of jasmonate-induced increases in tobacco alkaloids, phenolics, and diterpene glycosides in Nicotiana attenuata. Journal of Agricultural and Food Chemistry 49: 3553-3558.

Kessler, A., and I. T. Baldwin. 2001. Defensive function of herbivore-induced plant volatile emissions in nature. Science 291:2141-2144.

Koiwa, H., R. A. Bressan, and P. M. Hasegawa. 1997. Regulation of protease inhibitors and plant defense. Trends in Plant Science 2:379-384.

Maynard-Smith, J. 1989. Evolutionary genetics. Oxford University Press, Oxford, UK.

Lynds, G. Y., and I. T. Baldwin. 1998. Fire, nitrogen, and defensive plasticity. Oecologia 115:531-540.

McCloud, E. S., and I. T. Baldwin. 1997. Herbivory and caterpillar regurgitants amplify the wound-induced increases in jasmonic acid but not nicotine in Nicotiana sylvestris. Planta 203:430-435.

McGurl, B., G. Pearce, M. Orozco-Cardenas, and C. A. Ryan. 1992. Structure, expression, and antisense: inhibition of the systemin precursor gene. Science 255:1570-1573.

Mochizuki, A., Y. Nishizawa, H. Onodera, Y. Tabei, S. Toki, Y. Habu, M. Ugaki, and Y. Ohashi. 1999. Transgenic rice plants expressing a trypsin inhibitor are resistant against stem borers, Chilo suppressalis. Entomologia Experimentalis et Applicata 93:173-178.

Ogawa, M., T. Kusano, N. Koizumi, M. Katsumi, and H. Sano. 1999. Gibberellin-response genes: high level of transcript accumulation in leaf sheath meristemic tissue from Zea mays. Plant Molecular Biology 40:645-657.

Ohnmeiss, T. E., and I. T. Baldwin. 1994. The allometry of nitrogen allocation to growth and an inducible defense under nitrogen-limited growth. Ecology 75:995-1002.

Ryan, C. A. 1990. Protease inhibitors in plants: genes for improving defenses against insects and pathogens. Annual Review of Phytopathology 28:425-449.
Salmore, A. K., and M. D. Hunter. 2001. Elevational trends in defense chemistry, vegetation, and reproduction. Journal of Chemical Ecology 27:1713-1727.

SAS 1998. StatView. SAS Institute, Cary, North Carolina, USA.

Thaler, J. 1999. Induced resistance in agricultural crops: effects of jasmonic acid on herbivory and yield in tomato plants. Environmental Ecology 28:30-37.

van Dam, N. M., and I. T. Baldwin. 1998. Costs of jasmonateinduced responses in plants competing for limited resources. Ecology Letters 1:30-33.

van Dam, N. M., and I. T. Baldwin. 2001. Competition mediates costs of jasmonate-induced defenses, nitrogen acquisition and transgenerational plasticity in Nicotiana attenuata. Functional Ecology 15:406-415.

van Dam, N. M., U. Hermenau, and I. T. Baldwin. 2001a. Instar-specific sensitivity of specialist Manduca sexta larvae to induced defences in their host plant Nicotiana attenuata. Ecological Entomology 26:578-586.

van Dam, N. M., M. Horn, M. Mareš, and I. T. Baldwin. $2001 b$. Ontogeny constrains the systemic protease inhibitor response in Nicotiana attenuata. Journal of Chemical Ecology 27:547-568.

Voelckel, C., U. Schittko, and I. T. Baldwin. 2001. Herbivoreinduced ethylene burst reduces fitness costs of jasmonateand oral secretion-induced defenses in Nicotiana attenuata. Oecologia 127:274-280.

Winterer, J., and J. Bergelson. 2001. Diamondback moth compensatory consumption of protease inhibitor-transformed plants. Molecular Ecology 10:1069-1074.

Winz, R. A., and I. T. Baldwin. 2001. Molecular interactions between the specialist herbivore Manduca sexta and its natural host Nicotiana attenuata. IV. Insect-induced ethylene reduces jasmonate-induced nicotine accumulation by regulating putrescine $\mathrm{N}$-methyltransferase transcripts. Plant Physiology 125:2189-2202.

Wolfson, J. L., and L. L. Murdock. 1990. Growth of Manduca sexta on wounded tomato plants: role of induced proteinase inhibitors. Entomologia Experimentalis et Applicata 54: 257-264. 